
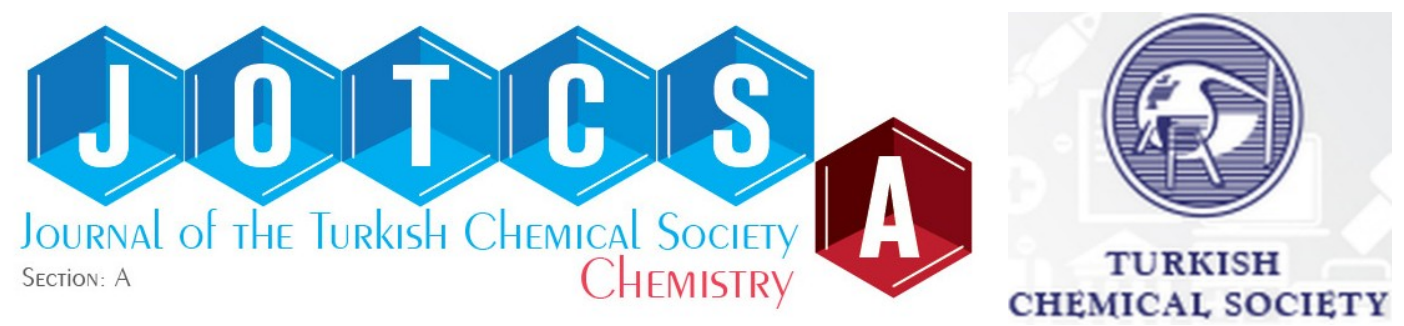

\title{
Hydrothermal Synthesis of Fluorescent Schiff Base Functionalized Carbon Dot Composite for The Removal of Cd(II) Ions from Aqueous Solution: Optical, Equilibrium and Kinetic Studies
}

\author{
Nworie Felix Sunday ${ }^{1 *}$ and Ebunoha Jane Ifeoma ${ }^{1}$ D \\ ${ }^{1}$ Department of Industrial Chemistry, Ebonyi State University, \\ PMB 053 Abakaliki, Ebonyi State, Nigeria.
}

\begin{abstract}
The search for nanoparticle metal chelator biomarker has been on the rise in recent years. In this study, bis(salicylidene)ethylenediamine (SALEN) functionalized carbon dot derived from waste banana peels was synthesized using facile hydrothermal technique and the optical biomarker and adsorption properties of the highly fluorescent red nanomaterial was studied. The carbon dot and its functionalized counterpart were characterized using FTIR, SEM/EDX, and UV-Visible spectrophotometry. Evaluation of the optical properties of the yellowish brown carbon dot and reddish highly luminescent functionalized carbon dot indicated band gap energy values of 1.85 and $2.04 \mathrm{eV}$, respectively. Extraneous variables such as effect of initial metal ion concentration, $\mathrm{pH}$, and contact time were studied in the batch extraction process for the sorption of Cd(II) ions from aqueous solution. The sorption of $\mathrm{Cd}(\mathrm{II})$ ion was observed to be highest at $\mathrm{pH} 5$ with $99.3 \%$ removal efficiency. The adsorption isotherm and kinetic models indicated interplay of physisorption and chemisorption processes. The mechanism for the chelation of $\mathrm{Cd}(\mathrm{II})$ ions onto the surface of the functionalized carbon dot was mainly governed by inner sphere chelation and ion exchange. Reusability of the material was evaluated using adsorption-desorption experiments. Results of the study indicated the potential of the functionalized carbon dot as (i) semiconductor materials with strong photoluminescence at the visible region which could be used as environmental biomarker and as sensor, and (ii) effective, efficient and low cost adsorbent for remediating $\mathrm{Cd}(\mathrm{II})$ ions contaminated environment.
\end{abstract}

Keywords: Adsorption studies, carbon dot nanoparticle, cadmium, adsorption mechanism, optical biomarker.

Submitted: July 29, 2020. Accepted: December 13, 2020.

Cite this: Nworie FS, Ebunoha Jl. Hydrothermal Synthesis of Fluorescent Schiff Base Functionalized Carbon Dot Composite for The Removal Of $\mathrm{Cd}(\mathrm{II})$ Ions From Aqueous Solution: Optical, Equilibrium and Kinetic Studies. JOTCSA. 2021;8(1):137-54.

DOI: https://doi.org/10.18596/jotcsa.775739.

*Corresponding author, e-mail: nworie.sunday@ebsu.edu.ng, Tel: +234 8034813342.

\section{INTRODUCTION}

Deleterious heavy metals such as cadmium pose serious harmful health and environmental hazard as they are regarded as destructive contaminant due to their bio-accumulative and non-degradable properties (1). The anthropogenicity, teratogenicity, and carcinogenicity of cadmium and its implicative role in renal failure and cancer-related deformities have been widely reported (2). As a result of the health and environmental problems associated with ingestion of cadmium in its bioaccumulation in the ecosystem, its removal from environmental matrices using an ecofriendly technique has remained an enormous task. Recently, researchers have employed several techniques for the removal of heavy metals cadmium inclusive from environmental matrices (3). The commonly used techniques include electrolysis, ion 
exchange, chemical precipitation, and adsorption (3$6)$. The techniques listed are faced with one limitation or the other such as high cost, waste of time, secondary waste generation, and lack of equipment (7). The evolution of nanomaterial technology as an alternative to the techniques has succeeded in proffering solution to the myriads of problems hitherto observed in heavy removal processes (8-9). Nanoparticles is currently the preferred adsorption material due to their unique properties like high surface area, high chemical stability, rapid adsorption potentials, and high adsorption capacity (8). As a consequence, nanoparticles have greater potentials to adsorb metal ions with high adsorption capacity in a rapid batch or column modulated process. There has been rising concern all over the world on waste management practices that is environmentally benign. Carbon dots from waste pectin and alginate sources have been recently researched on (10). A majority of carbon dots have been applied in theranostic purposes and other medical, photocatalytic and fluorescence studies (11). The use of carbon dots in the removal of metal ions from aqueous matrices started lately with current research on the modification in the structural, magnetic and molecular moiety using different conjugants $(10,12)$. The development of excellent functionalized carbon quantum dot nanomaterial for the adsorption of cadmium from aqueous solution has been reported, however, carbon quantum dot is potentially toxic compared to carbon dot (7). The use of hydrothermal synthetic technique in the preparation of carbon dot is advantageous because of relatively mild operating conditions (reaction temperatures $<300{ }^{\circ} \mathrm{C}$ ), one-step synthetic procedure, environmental friendliness, and good dispersion in solution (1). Studies have noted that carbon dots with surface immobilization exhibit high fluorescent properties whereas the nonfunctionalized carbon nanoparticles are weakly fluorescent. Consequently, fluorescence results due to surface charge separation with cations and anions (holes and electrons) trapped causing radiative recombination. Carbon dots have been shown to exhibit excellent properties not limited to photostability, chemical inertness, bio-consistency, nontoxicity, bright fluorescence, photodynamic and photo induced redox (electron donor- acceptor) properties $(7,13)$.

Optical properties of nanomaterial and functionalized counterparts have attracted much attention and concern in recent time because of the myriads of their important technological applications, like bioimaging, biosensing, optoelectronics, photocatalysis and water splitting for energy conversion $(7,14)$. Carbon dots nanomaterial are fluorescent with the functionalized counterpart exhibiting greater fluorescence over the visible spectrum region and little or no extension into the near-infrared region (15). Carbon dots and its functionalized counterpart have recently emerged as a new hybrid nanoparticle of high fluorescence and gradually replacing the conventional semiconductor quantum dots. This new field of research is rapidly advancing with countless researchers on the synthesis and applications of the non-toxic, low cost and environmentally benign nanomaterial in different technological processes and investigations.

In the work reported in this paper, carbon dot was synthesized from waste banana peels and thereafter functionalized using a bis Schiff base bis(salicylidene)ethylendiamine (SALEN). The SALEN functionalized carbon dot was then characterized using ultraviolet-visible, Fourier transform infrared, scanning electron microscopy, and energy dispersive $X$-ray to obtain the optical properties, functional group, structural and elemental compositions, respectively. The functionalized carbon dot nanomaterial was further applied for the adsorptive removal of cadmium(II) ions from aqueous solution. The mechanism of the removal of cadmium was investigated using equilibrium and kinetic data after studying the influence of extraneous variables of time, $\mathrm{pH}$ and initial metal ion concentration. The chelation mechanism of $\mathrm{Cd}(\mathrm{II})$ ions onto the functionalized carbon dot was proposed based on the result from $\mathrm{pH}$ analysis.

\section{EXPERIMENTAL SECTION}

\section{Materials and methods}

Reagents: The following analytical grade reagents were obtained from Merck Germany and used for the synthesis: Cadmium sulfate, hydrochloric acid, aqueous ammonia, salicyladehyde, ethylenediamine, sodium hydroxide, ethanol.

Apparatus: The following apparatuses were used for measurement and characterization: Drying oven (model DHG) for drying of samples, Buck 205 Scientific Atomic Absorption Spectrophotometer for measurement of concentration of samples, Phenomprox by Phenom world Eindhoven, The Netherlands for structural morphology and elemental composition measurement, Cary 630 Agilent Technologies, USA for functional group determination, UV-Vis Spectrophotometer (model Genesis 10S) was used to obtain electronic spectra of the nanoparticle and functionalized counterpart. Rotary shaker (RF-12 Remi equipment) was used for all equilibrations and shakings. 


\section{Methods}

Synthesis of the carbon dot from banana peel: Fresh banana peel was obtained from Abakpa main market in Abakaliki, Ebonyi State, Nigeria using polyethene bags. Carbon dot was prepared using a modified literature method (1). It was washed repeatedly with distilled water, air-dried and the juice extracted using using a grinder. In the synthesis, $150 \mathrm{~g}$ of the washed banana peel was ground to a paste and squeezed to extract the juice. Exactly $30 \mathrm{~mL}$ of the banana peel juice was mixed with $8.0 \mathrm{~mL}$ of deionized water and $10 \mathrm{~mL}$ of $25 \%(\mathrm{v} / \mathrm{v}) \mathrm{NH}_{4} \mathrm{OH}$ solution. The mixture was then transferred into a $250 \mathrm{~mL}$ conical flask and heated using a domestic microwave oven for $6 \mathrm{~min}$. Immediately after cooling to room temperature, the mixture was centrifuged at $600 \mathrm{rpm}$ for $30 \mathrm{~min}$ and washed several times with double distilled water to remove all the unreacted molecules. Then the carbon dots-based nanoparticle obtained by evaporation was collected and dried at a temperature of $60{ }^{\circ} \mathrm{C}$ for 30 $\min$.

Synthesis of bis(salicylidene) ethylenediamine (SALEN): This was prepared according to the literature procedure (16). Ethylenediamine (22.475 g) was gradually added with stirring to $91.336 \mathrm{~g}$ of salicyladehyde in a $500 \mathrm{~cm}^{3}$ beaker. The yellow crystal formed was recrystallized twice from carbon tetrachloride to give the golden yellow crystals [64.45\% yield, $\left.\mathrm{mp} 121 \pm 1{ }^{\circ} \mathrm{C}\right]$.

Synthesis of SALEN functionalized carbon dot: SALEN functionalized carbon dot nanoparticle was obtained by weighing $2.94 \mathrm{~g}$ of carbon dot into a $250 \mathrm{~mL}$ beaker and $10 \mathrm{~mL}$ of the $0.5 \%$ SALEN solution added. The mixture was stirred for $6 \mathrm{~h}$ at ambient temperature and the SALEN functionalized carbon dot was separated by filtration, washed several times with distilled water to remove unreacted SALEN, and then dried at a temperature of $90{ }^{\circ} \mathrm{C}$ for $1 \mathrm{~h}$.

Adsorption studies with the SALEN functionalized carbon dot nanoparticle: Batch experiments were performed to elucidate the metal chelation properties of the SALEN functionalized carbon dot for the preconcentration of $\mathrm{Cd}(\mathrm{II})$ ions from aqueous solution. The experiment was conducted to obtain the requisite data by varying different conditions of time of contact, $\mathrm{pH}$ and initial metal ion concentration. The metal chelation properties was investigated by adding $0.1 \mathrm{~g}$ of the SALEN functionalized carbon dot to $10 \mathrm{~mL}$ of different concentrations of cadmium (II) solution $(0.0448,0.448$ and $4.48 \mathrm{mg})$ and the mixture equilibrated at room temperature $\left(30 \pm 1{ }^{\circ} \mathrm{C}\right)$ for 3 min using mechanical shaker at $100 \mathrm{rpm}$ and the resulting solution was filtered. The sorption kinetics was studied by varying the time between 2-6 min while $\mathrm{pH}$ was varied between 2-11. To determine the maximum time needed for adsorption and $\mathrm{pH}$ of maximum adsorption, $0.1 \mathrm{~g}$ of the functionalized carbon dot was mixed with $10 \mathrm{~mL}$ of $0.01 \mathrm{M} \mathrm{Cd}$ (II) ion in the vessel. In both cases, the mixture was equilibrated at room temperature $\left(30 \pm 1{ }^{\circ} \mathrm{C}\right)$ for 3 min using a mechanical shaker at $100 \mathrm{rpm}$ and resulting solution filtered and kept for analysis. Regeneration and reusability experiment was performed to access the economical and ecofriendliness of the composite. In the study, $5 \mathrm{~mL}$ of different concentrations of $\mathrm{HCl}(1,0.1,0.01,0.001 \mathrm{M})$ were equilibrated with $0.1 \mathrm{~g}$ of the $\mathrm{Cd}(\mathrm{II})$ loaded nanocomposite at different time intervals of $5,10,15$, 20,25 , and $30 \mathrm{~min}$. The $\mathrm{Cd}(\mathrm{II})$ ion in the combined filtrate after triplicate analysis was determined using AAS. The distribution coefficient $\left(K_{d}\right)$, dosage concentration $(S)$, the adsorption capacity (" $\alpha$ "), percentage of metal chelated (\%) of $\mathrm{Cd}(\mathrm{II})$ ion and quantity of cadmium chelated (qt) at time $t$ were evaluated using Equations 1-5 respectively.

$$
\begin{gathered}
K_{d}=\frac{\text { Amount of metal } \text {, adsorbent }}{\text { amount of metal , solution }} \times \frac{1}{S} \\
S=\frac{m}{V} \\
\alpha=\frac{\left(C_{0}-C_{e}\right) V}{m} \\
\% \text { cadmium, chelated }=\frac{C_{0}-C_{e}}{C_{0}} \times 100 \\
q_{t}=\frac{\left(C_{0}-C_{t}\right) V}{m}
\end{gathered}
$$

$\mathrm{C}_{0}(\mathrm{mg} / \mathrm{L}), \mathrm{C}_{\mathrm{e}}(\mathrm{mg} / \mathrm{L}), \mathrm{C}_{\mathrm{t}}(\mathrm{mg} / \mathrm{g}), \mathrm{V}(\mathrm{L})$ and $\mathrm{m}(\mathrm{g})$ stands for the initial $\mathrm{Cd}(\mathrm{II})$ concentration, final concentration of the cadmium(II) ion, concentration of $\mathrm{Cd}$ (II) ion at time $t$, volume of aqueous solution, and weight of SALEN functionalized carbon dot respectively. The simulation of the metal chelation properties was modeled using linear adsorption models of Langmuir and Freundlich. The mass transfer and kinetics of chelation of $\mathrm{Cd}(\mathrm{II})$ onto SALEN-functionalized carbon dot was studied by plotting the equation of line of best fit using the simulated data applied to pseudo-first order and pseudo-second order models. The adequacy cum applicability of the design in relation with the best fit model for the process was evaluated using the 
coefficient of determination $\left(R^{2}\right)$. To ensure the adequacy, accuracy, and reproducibility of the process, triplicate experiments were conducted and mean values which are reproducible were used for further data simulation.

\section{RESULTS AND DISCUSSION}

To assess the nature, composition, structure, optical and adsorbent characteristics of the SALEN functionalized carbon dot and the $\mathrm{Cd}$ adsorption from aqueous solution AAS, FTIR, SEM/EDX, and UV-Vis analysis were performed.

\section{EDX Analysis}

The percentage elemental composition of the SALEN functionalized carbon dot before and after adsorption as given by EDX analysis is shown in (Table 1 and 2 ) and (Fig 1 and 2) respectively. The percentage weight concentration of the elements in the SALEN functionalized carbon dot could be seen to be $66.20 \%$ carbon, $15.24 \%$ oxygen, $5.22 \%$ potassium, $3.27 \%$ nitrogen, $1.72 \%$ cadmium, $1.46 \%$ calcium, $1.28 \%$ silicon, $1.15 \%$ chlorine, $0.96 \%$ sulfur, $0.95 \%$ aluminum, $0.91 \%$ iron, $0.78 \%$ phosphorus, $0.58 \%$ magnesium, and $0.29 \%$ sodium. For the cadmium loaded SALEN functionalized carbon dot, the weight concentration of the elements are $57.33 \%$ carbon,
$11.49 \%$ oxygen, $0.48 \%$ potassium, $0.83 \%$ of nitrogen, $19.19 \%$ cadmium, $1.63 \%$ calcium, $1.02 \%$ silicon, $2.96 \%$ chlorine, $1.70 \%$ sulfur, $0.87 \%$ iron, $0.59 \%$ phosphorus, $0.30 \%$ sodium, $0.84 \%$ aluminum, and $0.31 \%$ magnesium. From the result, it could be observed that the weight of $\mathrm{Cd}$ increased from $1.72 \%$ before adsorption to $19.19 \%$ after adsorption indicating the entrapment of the element onto the microporous nanoparticle.

Table 3 shows the surface polar functional group, hydrophobicity, and cation exchange capacity of the SALEN functionalized and unfunctionalized carbon dot nanomaterial. The result indicated higher atomic ratios of $(\mathrm{O}+\mathrm{N}) / \mathrm{C}$ for the SALEN functionalized carbon dot nanomaterial than the unfunctionalized counterpart. The implication is that the functionalized carbon dot has greater surface polar groups and would lead to greater adsorption capacity compared to the unfunctionalized counterpart as more binding sites are exposed for conjugation and entrapment of both anionic and cationic species. The high O/C atomic ratios of the functionalized carbon dot in relation to the unfunctionalized counterpart indicated high cation exchange capacity, low hydrophobicity of the functionalized nanomaterial and greater metal chelation ability (4).

Table 1: EDX of SALEN functionalized carbon dot (CD2) showing elemental composition (\%).

\begin{tabular}{llll}
$\begin{array}{l}\text { Atomic } \\
\text { Number }\end{array}$ & Element Name & $\begin{array}{l}\text { Atomic } \\
\text { Conc. }\end{array}$ & $\begin{array}{l}\text { Weight } \\
\text { Conc. }\end{array}$ \\
\hline 6 & Carbon & 77.59 & 66.20 \\
8 & Oxygen & 13.41 & 15.24 \\
19 & Potassium & 1.88 & 5.22 \\
7 & Nitrogen & 3.29 & 3.27 \\
48 & Cadmium & 0.22 & 1.72 \\
20 & Calcium & 0.51 & 1.46 \\
14 & Silicon & 0.64 & 1.28 \\
17 & Chlorine & 0.46 & 1.15 \\
16 & Sulfur & 0.42 & 0.96 \\
13 & Aluminum & 0.49 & 0.95 \\
26 & Iron & 0.23 & 0.91 \\
15 & Phosphorus & 0.35 & 0.78 \\
12 & Magnesium & 0.34 & 0.58 \\
11 & Sodium & 0.18 & 0.29 \\
\hline
\end{tabular}




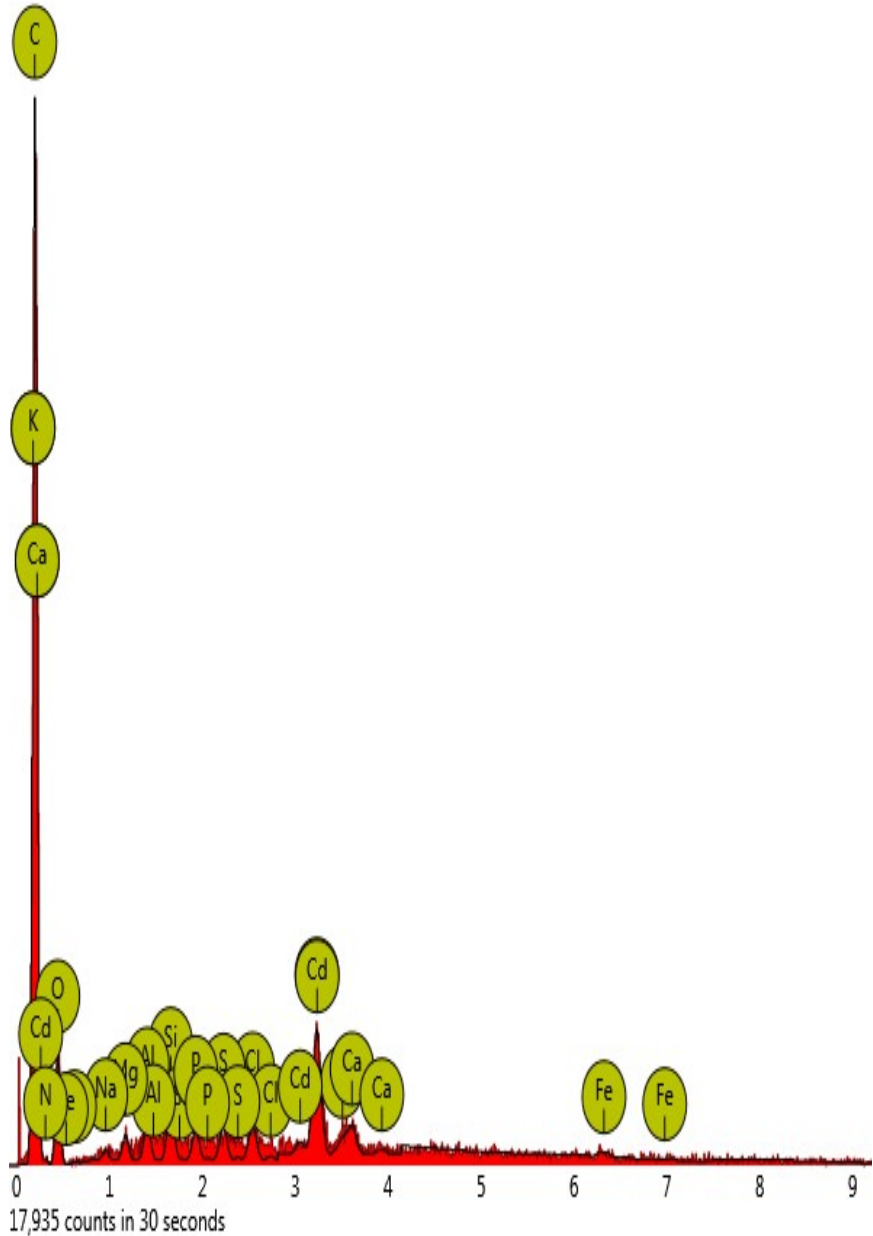

Figure 1: EDX of SALEN functionalized carbon $\operatorname{dot}(C D 2)$ showing elemental composition.

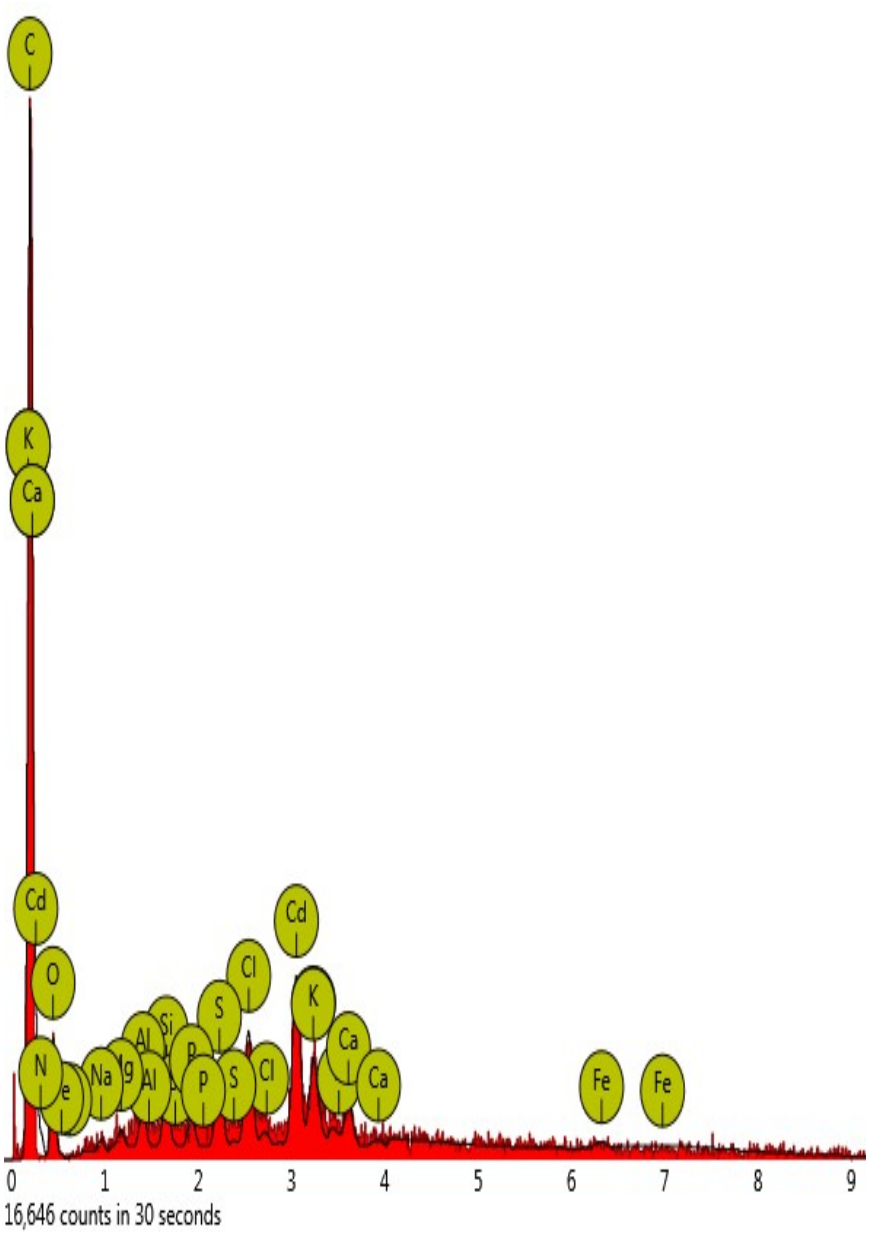

Figure 2: EDX of cadmium loaded SALEN functionalized carbon dot showing elemental composition.

Table 2: EDX of cadmium-loaded carbon dot (CD3) showing elemental composition (\%)

\begin{tabular}{llll}
\hline $\begin{array}{l}\text { Atomic } \\
\text { Name }\end{array}$ & Element & $\begin{array}{l}\text { Atomic } \\
\text { Conc. }\end{array}$ & $\begin{array}{l}\text { Weight } \\
\text { Conc. }\end{array}$ \\
\hline 6 & Carbon & 78.68 & 57.33 \\
48 & Cadmium & 2.81 & 19.19 \\
8 & Oxygen & 12.29 & 11.94 \\
17 & Chlorine & 1.38 & 2.96 \\
16 & Sulfur & 0.87 & 1.70 \\
20 & Calcium & 0.67 & 1.63 \\
14 & Silicon & 0.60 & 1.02 \\
26 & Iron & 0.26 & 0.87 \\
13 & Aluminum & 0.51 & 0.84 \\
7 & Nitrogen & 0.98 & 0.83 \\
15 & Phosphorus & 0.31 & 0.59 \\
19 & Potassium & 0.20 & 0.48 \\
12 & Magnesium & 0.21 & 0.31 \\
11 & Sodium & 0.22 & 0.30 \\
\hline
\end{tabular}


Table 3: Comparison of the surface polar functional group, cation exchange capacity and hydrophobicity of SALEN functionalized and unfunctionalized carbon dot.

\begin{tabular}{llllll}
\hline & $\begin{array}{l}\text { Carbon } \\
(\mathrm{C})\end{array}$ & $\begin{array}{l}\text { Oxygen } \\
(\mathrm{O})\end{array}$ & $\begin{array}{l}\text { Nitrogen } \\
(\mathrm{N})\end{array}$ & $(\mathrm{O}+\mathrm{N}) / \mathrm{C}$ & $\mathrm{O} / \mathrm{C}$ \\
\hline Functionalized carbon dot & 77.59 & 13.41 & 3.29 & 0.22 & 0.17 \\
Unfunctionalized carbon dot & 78.68 & 12.21 & 0.98 & 0.17 & 0.15 \\
\hline
\end{tabular}

\section{SEM Analysis}

The surface morphology of the SALEN functionalized and cadmium loaded SALEN-functionalized carbon dot nanoparticle was characterized using SEM/EDX and the micrograph shown in Figures 3 and 4, respectively. The microporous structure was observed with $10000 \mathrm{X}$ resolution and the image was taken with a particle size of $10 \mu \mathrm{m}$. The SEM images of carbon dot from banana peel showed that it contained an irregular porous surface. Figures 3 and 4 represent SEM micrograph of the CD2 and CD3, respectively, at different magnifications. From the SEM image of CD2 it could be observed that the surface morphology is rough, irregular and highly corrugated providing enough micropores that could enhance adsorption. Similar observations have been made on related agricultural biowaste of saw dust and brewers spent grain $(5,17)$. The SEM image of CD3 could be seen as clusters of small particles not originally present on $\mathrm{CD} 2$. This could be the indication of $\mathrm{Cd}$ ions adsorbed to the surface of the nanoparticle. Similar observation have been made previously on the utilization of agrowaste material for the toxic hexavalent chromium removal (18).

\section{FTIR Analysis}

The result on FTIR indicating the surface functional groups as in Figures 5-7 revealed a number of absorption peaks characteristic of a complex structure. A broad band representing hydroxyl group($\mathrm{OH}$ ) was observed at $3265.1 \mathrm{~cm}^{-1}$ for carbon dot nanoparticle which shifted to $3261.4 \mathrm{~cm}^{-1}$ upon immobilization with SALEN and then to $3251.7 \mathrm{~cm}^{-1}$ after adsorption with $\mathrm{Cd}$. This band was attributed to $\mathrm{O}-\mathrm{H}$ stretching vibration present in polymeric species such as lignin and is due to intra and intermolecular hydrogen bonding (17). This is an indication of free hydroxyl groups at the surface of the functionalized carbon dot nanoparticle and its functionalized counterpart (16). The bands observed at 2926.0, 2922.2, and $2926.0 \mathrm{~cm}^{-1}$ for CD1, CD2 and CD3, respectively, could be that of aliphatic $\mathrm{C}-\mathrm{H}$ groups (5).
The band observed at 1625.1, 1606.5, and $1606.0 \mathrm{~cm}$ 1 for $C D 1, C D 2$, and CD3, respectively, could be attributed to the carbonyl group $(\mathrm{C}=\mathrm{O})$ of unionized carboxylate stretching of carboxylic group while the peaks observed at 1028.7, 1021.3 and $1025.0 \mathrm{~cm}^{-1}$ for $\mathrm{CD1}, \mathrm{CD} 2$ and CD3, respectively, could be assigned to $\mathrm{C}=\mathrm{C}$ phenolic ring stretching vibration from lignin (17). The band observed at 1371.7, 1371.7 and $1375.4 \mathrm{~cm}^{-1}$ for CD1, CD2, and CD3 respectively could be assigned to C-N stretching of the amine group (5, 17). The intense band of 1244.9 and $1148.0 \mathrm{~cm}^{-1}$ observed between 2000-400 $\mathrm{cm}^{-1}$ region for CD1 and CD2 could have probably arisen from polysaccharide and could be assigned to $\mathrm{C}-\mathrm{O}, \mathrm{C}=\mathrm{C}$ or $\mathrm{C}-\mathrm{C}-\mathrm{O}$ stretching vibration of ether group of cellulose, hemicellulose or lignin $(5,17)$. The band that extends from 887.1 and $887.1 \mathrm{~cm}^{-1}$ to $738.0 \mathrm{~cm}^{-1}$ respectively for CD2 and CD3 could be ascribed to ester vibration of monosubstituted aromatic rings (17). Spectral band shift as observed in CD1, CD2 and CD3 is a confirmation of the immobilization of SALEN to the carbon dot and adsorption of $\mathrm{Cd}$ to the SALEN functionalized carbon dot nanoparticle.

\section{Optical / biomarker properties of the nanoparticle}

The UV-Visible spectra of the CD1 and CD2 is displayed in Figures 8 and 9. The carbon dot has a single absorption peak at $332 \mathrm{~nm}$ attributed to $\pi \rightarrow \pi^{*}$ transition of $\mathrm{C}=\mathrm{C}$ characteristic of all carbon dot nanoparticles (15). The absorption band of the carbon dots upon immobilization with a dopant SALEN was centred at $370 \mathrm{~nm}$ assigned to $\mathrm{n} \rightarrow \pi^{*}$ transition of $\mathrm{C}=0$ characteristic of $\mathrm{N}$ doped carbon dot nanomaterials (19-20). The cadmium loaded carbon dot showed strong reddish color which is attributed to tuneable photoluminescence character of amine moiety bonded carbon dots resulting from nucleophilic substitution and orbital resonance of the nitrogen conjugated system (15). The absorption coefficient, refractive index, reflectance, transmittance and dielectric constant values were evaluated using Eqs 6-10 (15). 


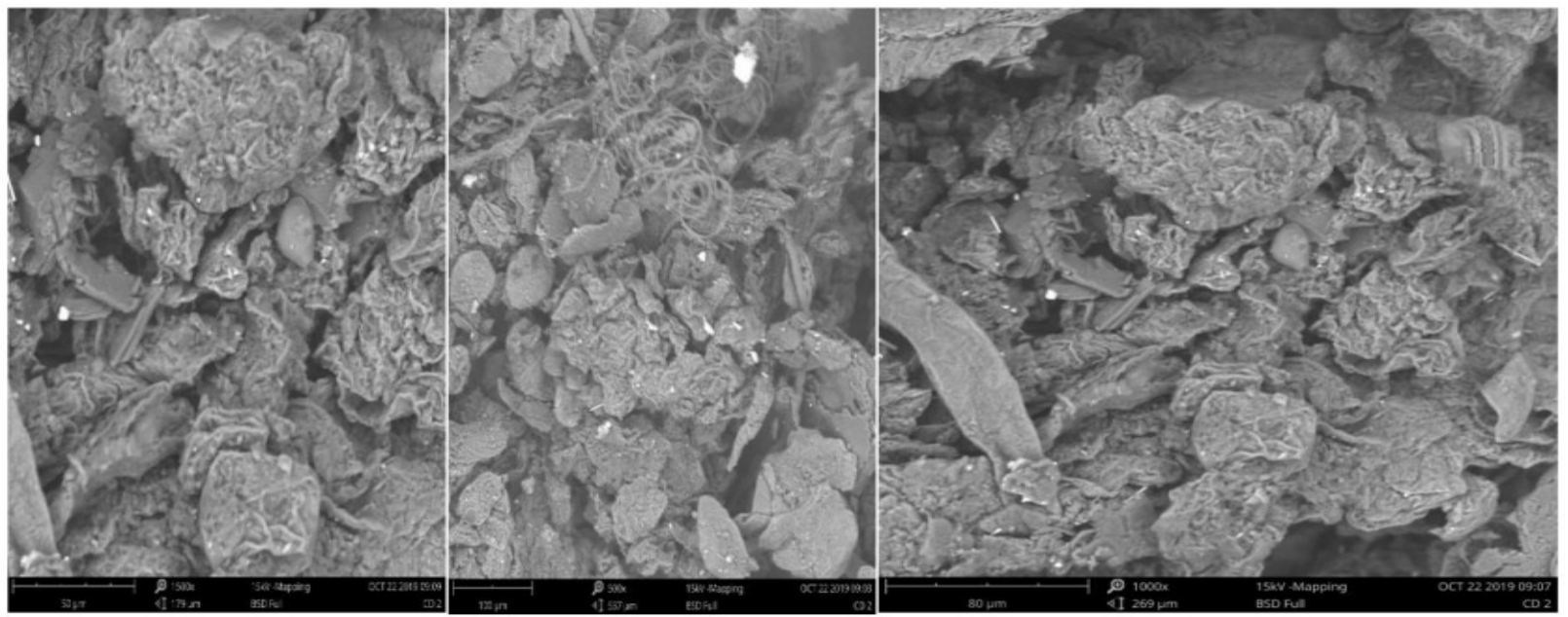

Figure 3: SEM Micrographs of SALEN functionalized carbon dot nanoparticle at different magnifications.
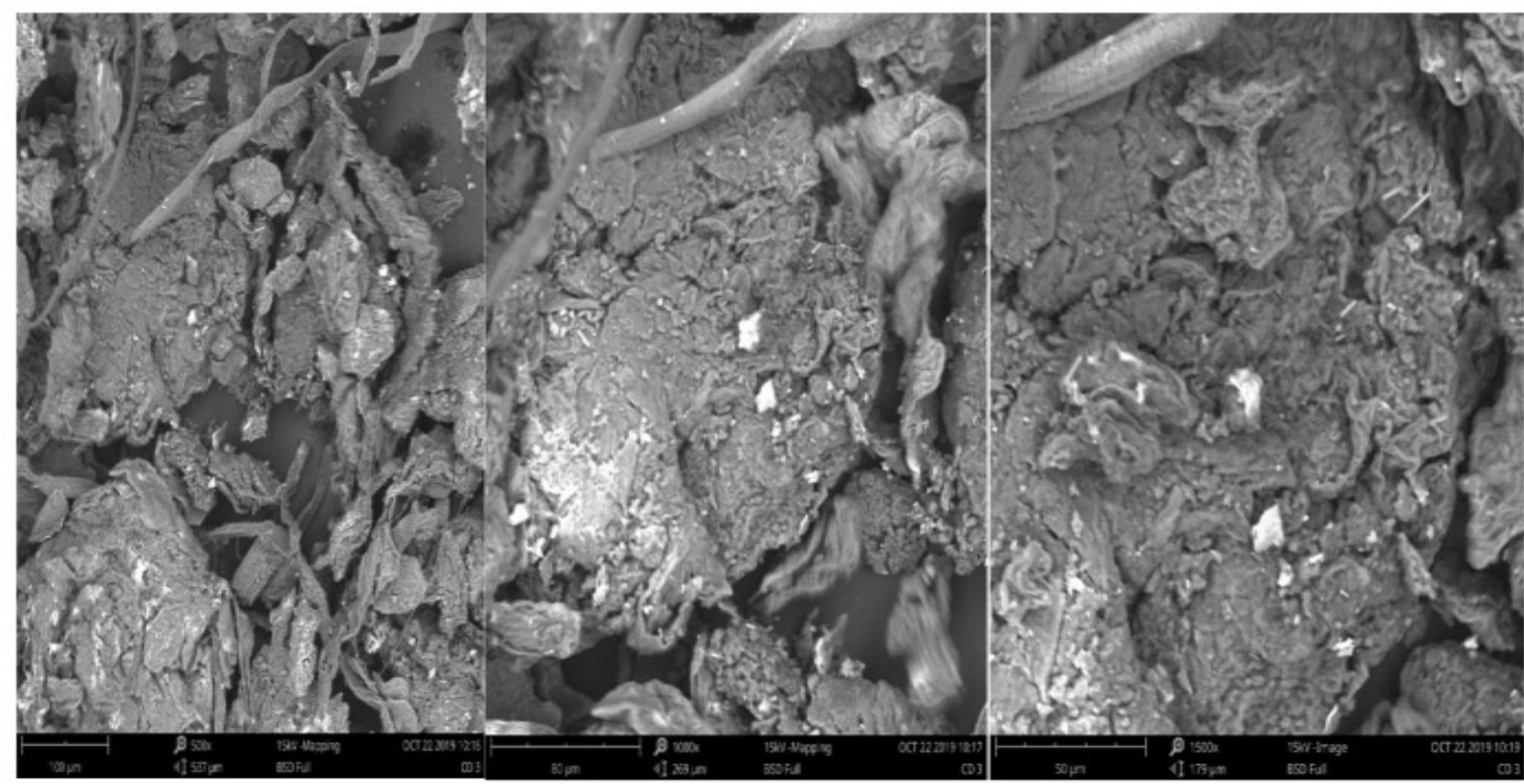

Figure 4: SEM Micrographs of cadmium loaded SALEN functionalized carbon dot nanoparticle at different magnifications. 
Nworie FS, Ebunoha JI. JOTCSA. 2021; 8(1): 137-154.

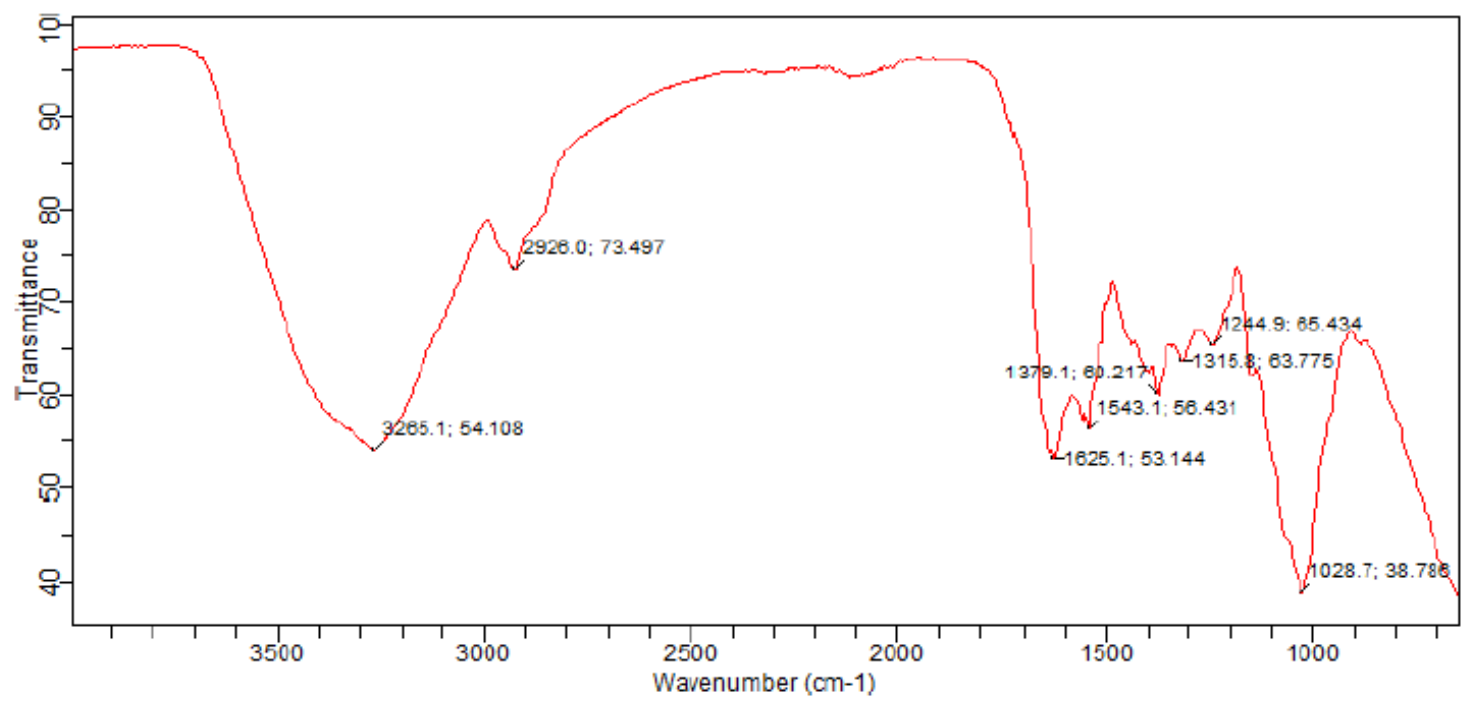

Figure 5: FTIR Absorption Bands $\left(\mathrm{cm}^{-1}\right)$ of carbon dot nanoparticle $($ carbon dot $=\mathrm{CD} 1)$.

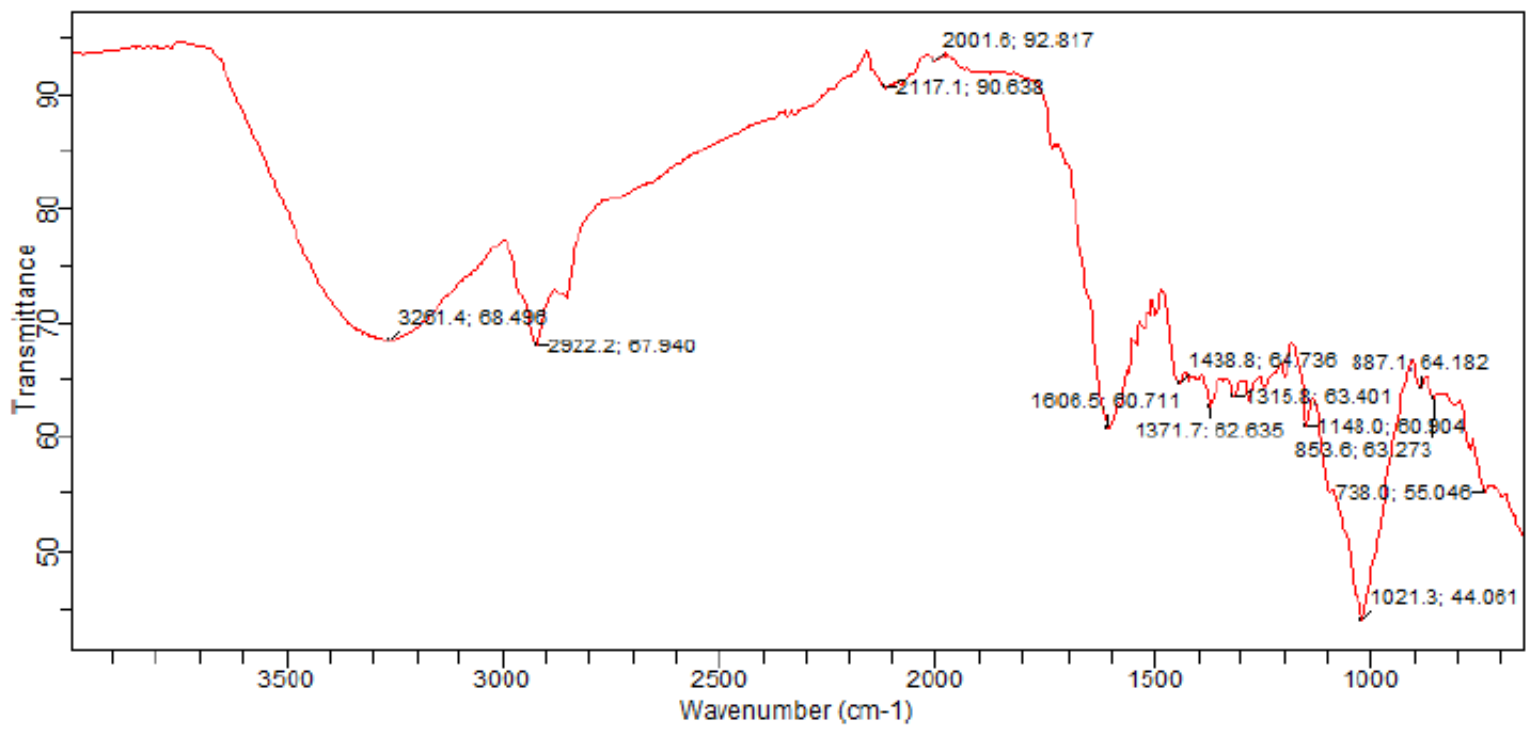

Figure 6: FTIR Absorption Bands $\left(\mathrm{cm}^{-1}\right)$ of SALEN-functionalized carbon dot (CD2). 


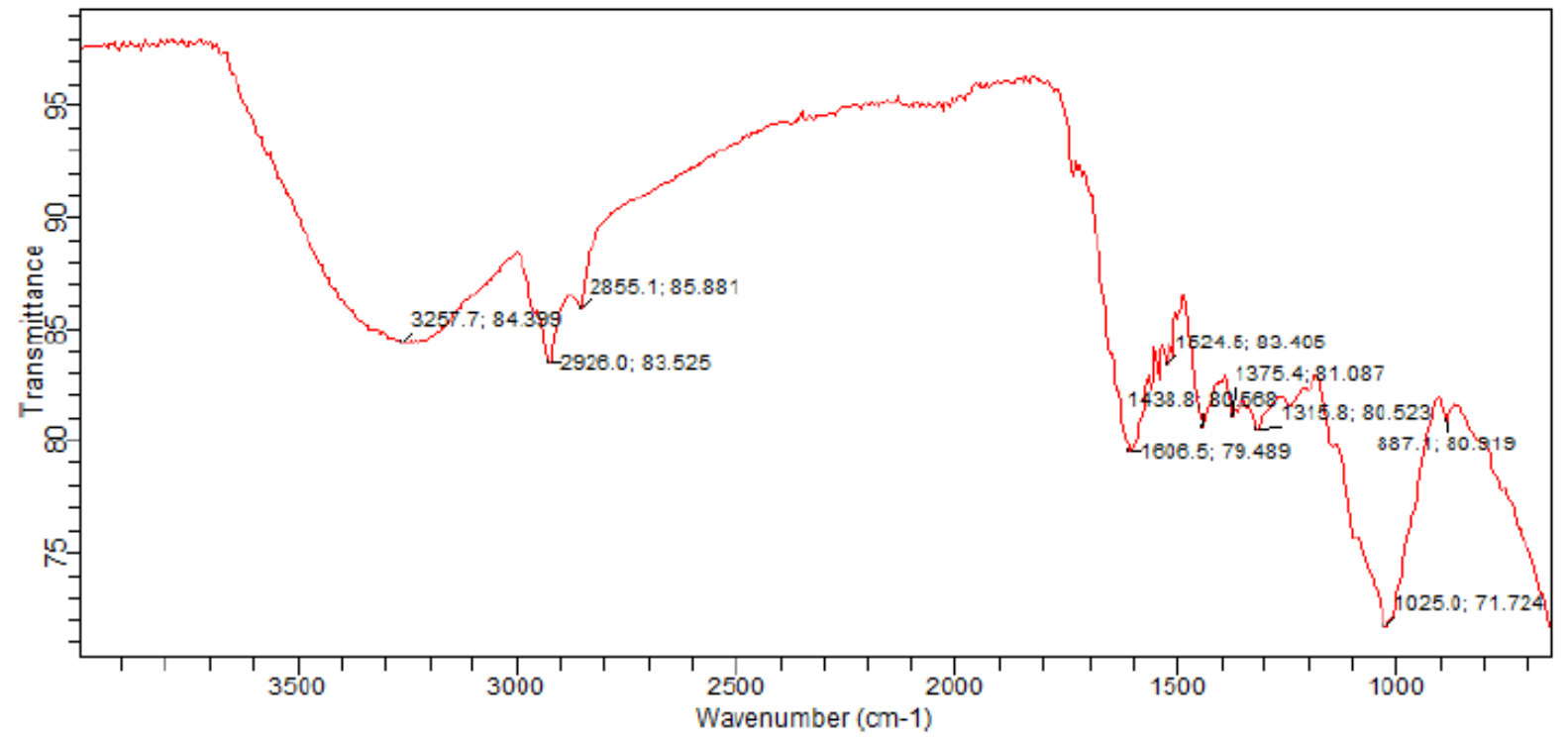

Figure 7: FTIR Absorption Bands $\left(\mathrm{Cm}^{-1}\right)$ of Cadmium loaded SALEN functionalized carbon dot (CD3).

$$
\begin{gathered}
\alpha=2.303 \times \frac{A}{T} \\
n=\frac{1+R^{1 / 2}}{1-R^{1 / 2}} \\
R=1-(A+T) \\
A=\log \left(\frac{1}{T}\right) \\
\in=n^{2}
\end{gathered}
$$

Where $\alpha, \mathrm{A}, \mathrm{T}, \mathrm{R}, \mathrm{n}$, and $\epsilon$ represent absorption coefficient, absorbance, transmittance, reflectance, refractive index, and dielectric constant, respectively. The absorption coefficient of the functionalized and unfunctionalized carbon dot was evaluated to be 0.03347 and 0.00167 , respectively. The result indicated that the functionalized carbon dot is a better optical material as the presence of the $\mathrm{N}$-dopant (SALEN) has increased the orbital resonance effect of the nanomaterial. The refractive index value of 3.44 and 3.52 of the functionalized and unfunctionalized carbon dot indicated a direct forbidden transition of the nanomaterial and its $\mathrm{N}$ doped counterpart (19). The reflectance, refractive index and dielectric constant of $0.302,0.688$, and 11.86 , respectively, of the functionalized and $0.3044,0.6906$ and 12.39, respectively, of the unfunctionalized counterpart indicated that they are strong sensing nanodot and could be used in bioimaging and biotracking especially in theranostic studies. The band gap energy $\left(E_{g}\right)$ was determined using the Herve-Vandamme relations (Eq 11) (19).

$$
n^{2}=1+\left(\frac{A}{E_{g}+B}\right)^{2}
$$

Where $A$ and $B$ are constants with values of $13.6 \mathrm{eV}$ and $3.34 \mathrm{eV}$, respectively, and $\mathrm{n}$ the refractive index.

The band gap energy of the functionalized carbon dot was obtained to be $2.04 \mathrm{eV}$ and the unfunctionalized carbon dot was evaluated to be $1.85 \mathrm{eV}$ characteristic of luminescence semiconductor materials with strong photoluminescence at the visible region $(15,21)$. The band gap energy of the functionalized nanomaterial was observed to be greater than the unfunctionalized probably because of optical band enhancement due to increased chelation or functionalization of the amine group and introduction of SALEN moiety impurity which modified the state of the carbon dot surface. The unfunctionalized carbon dot that is UV excited at $332 \mathrm{~nm}$ was strongly yellowish brown in color with tunable photoluminescence character from brownish to reddish emission and tunable band gap energy after conjugation through nucleophilic substitution with imine of Schiff base to form the functionalized highly luminescent carbon nanodot. 

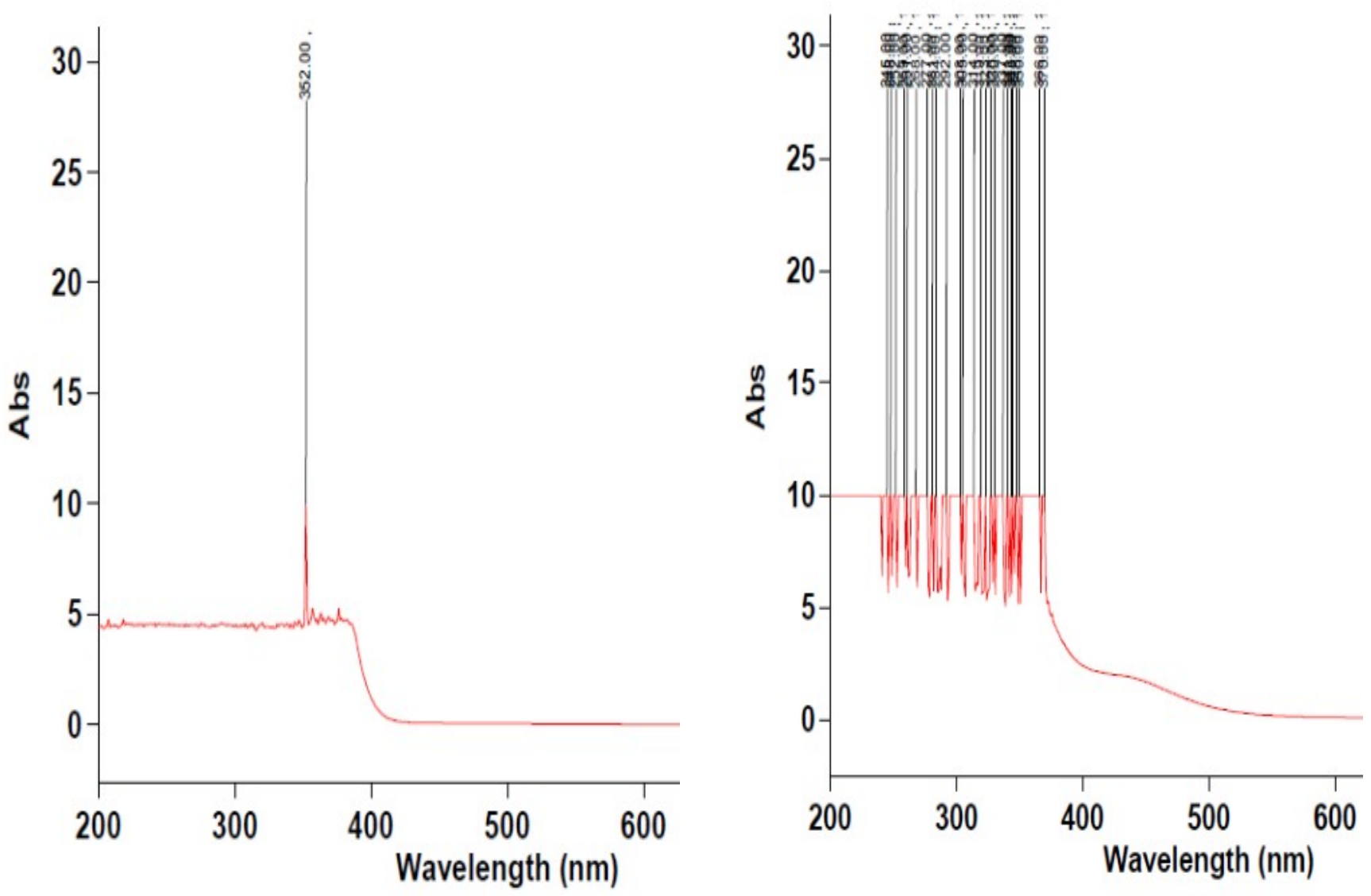

Figure 8: UV-Visible spectrum of banana peel carbon dot nanoparticle.

Figure 9: UV-Visible spectrum of SALEN-functionalized carbon dot.

Effect of initial amount of $\mathbf{C d}(\mathrm{II})$ ions

The effect of initial amount of $\mathrm{Cd}(\mathrm{II})$ ions captured on the surface of the functionalized carbon dot is illustrated in Fig 10. The study employed initial amounts of $0.0448,0.448$, and $4.48 \mathrm{mg}$. The percentage amount of $\mathrm{Cd}(\mathrm{II})$ ions adsorbed onto the functionalized carbon dot increased to maximum at

$4.48 \mathrm{mg}$ from $0.0448 \mathrm{mg}$ at $\mathrm{pH} 5$ and equilibration for $3 \mathrm{~min}$. The adsorptive sites of functionalized carbon dot were gradually filled up due to increase in the amount of $\mathrm{Cd}$ (II) ions adsorbed onto the surface until no more exposed surface resulting from intermolecular hydrogen bonding and hence regress in the amount adsorbed (22). 


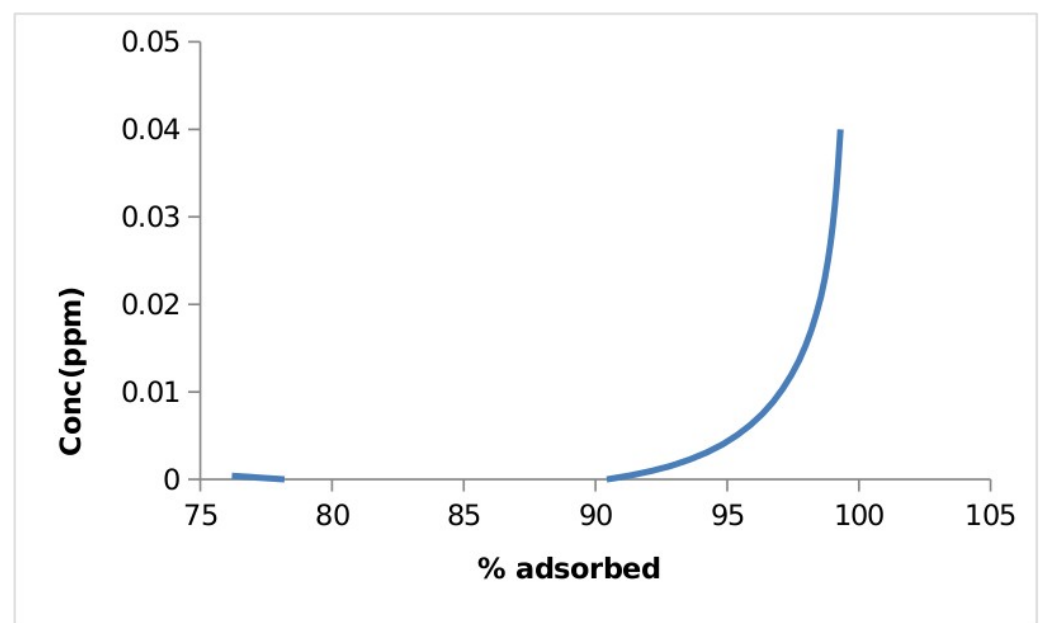

Figure 10: The effect of initial metal ion concentration on the percentage amount of Cd(II) chelated on the surface of the functionalized carbon dot at $\mathrm{pH} 5$.

\section{Effect of contact time}

The adsorption of $\mathrm{Cd}(\mathrm{II})$ ions onto the functionalized carbon dot at the $\mathrm{pH}$ of 5 and initial $\mathrm{Cd}(\mathrm{II})$ ion concentration of $0.0448 \mathrm{mg}$ was varied at different contact time as shown in Figure 11. As observed in the plot of percentage amount (\%) of $\mathrm{Cd}(\mathrm{II})$ ions adsorbed on the functionalized carbon dot against time, there was increase in contact time until equilibrium was attained at 3 min. As time of contact was further increased, there was no significant change in the percentage amount of $\mathrm{Cd}$ (II) adsorbed.
Reaching equilibrium for the functionalized nanosized adsorbent was rapid and remained fairly constant, implying the presence of uniform adsorption site which upon saturation by the adsorbate through hydrogen bonding and dipole-dipole interactions was filled up without more spaces or binding sites to occupy (22-23). The maximum adsorption indicating saturation point was observed at equilibrium and for a nano-based material it has been observed in similar study to lie at the same range (23-25).

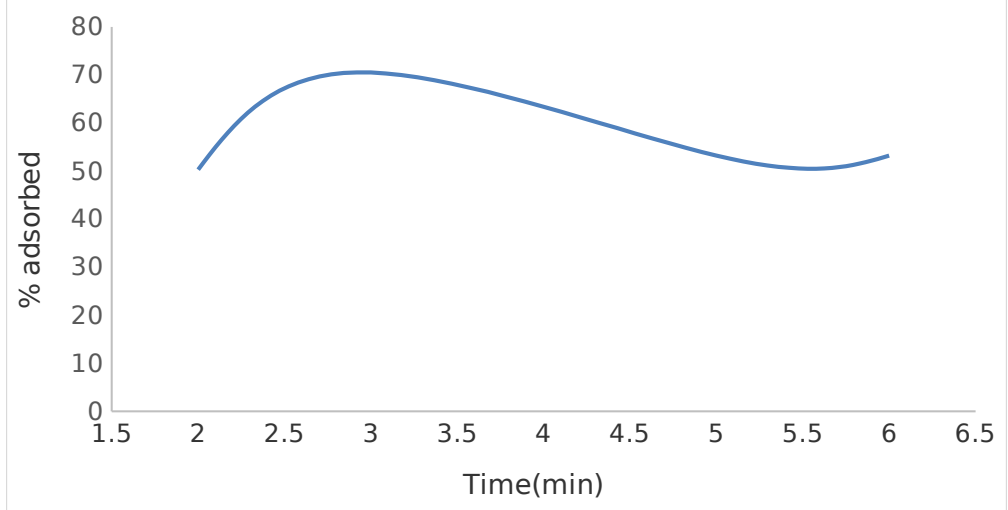

Figure 11: The effect of contact time on the percentage amount of $\mathrm{Cd}(\mathrm{II})$ chelated on the surface of the functionalized carbon dot at $\mathrm{pH} 5$.

\section{Effect of pH on the sorption of $\mathrm{Cd}(\mathrm{II})$ ions}

The effect of $\mathrm{pH}$ on the percentage amount of $\mathrm{Cd}(\mathrm{II})$ ions chelated is shown in Fig 12 at equilibration time of $3 \mathrm{~min}$ and initial $\mathrm{Cd}(\mathrm{II})$ ion concentration of 0.0448 $\mathrm{mg}$. The characteristics of every sorbent and the chemical nature of the metal ion to be chelated by the sorbent is greatly influenced by the $\mathrm{pH}$ of the solution.
As observed in Fig 10 there was an increase in the percentage amount of $\mathrm{Cd}(\mathrm{II})$ ions adsorbed at $\mathrm{pH} 2-3$ with a regress at $\mathrm{pH} 4$. The highest amount of $\mathrm{Cd}(\mathrm{II})$ ion adsorbed was observed at the optimal $\mathrm{pH}$ of 5 . The observed increase in the percentage amount of $\mathrm{Cd}$ (II) ions adsorbed at $\mathrm{pH} 10-11$ could be as a result of the formation of metal hydroxo species. Increased 
adsorption at $\mathrm{pH} 5$ could be as a result of the formation of protonated cationic complex between
SALEN functionalized carbon dot and the metal species.

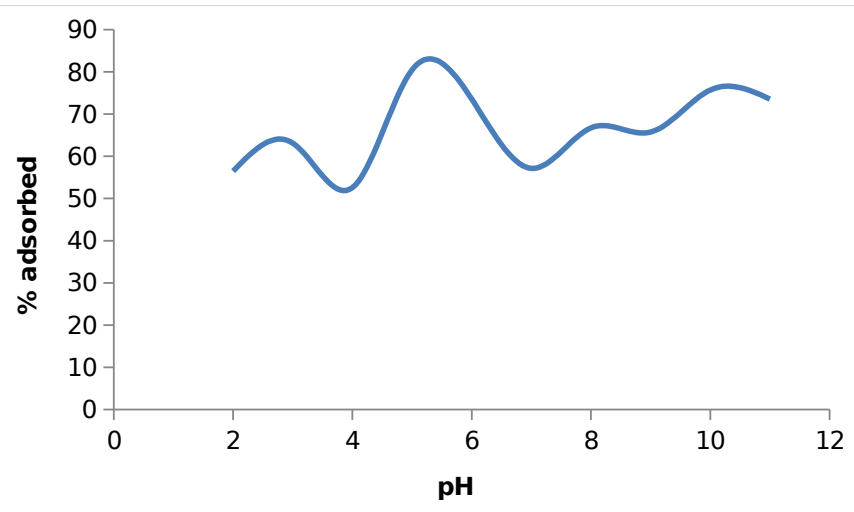

Figure 12: The effect of $\mathrm{pH}$ on the percentage amount of $\mathrm{Cd}(\mathrm{II})$ chelated on the surface of the functionalized carbon dot at 3 min equilibration.

\section{Adsorption isotherm and kinetic studies}

Adsorption isotherm models of Langmuir and Freundlich (22) were used to investigate the mechanistic behavior and relationship between the mass of Cd(II) ions adsorbed onto the surface of the SALEN-functionalized carbon dot and the processes that control the adsorption of the divalent metal cation on the functionalized carbon dot nanomaterial at constant $\mathrm{pH}$ and ambient temperature (303 $\pm 1 \mathrm{~K}$ ). The kinetics of the adsorption process was investigated using pseudo-first-order and pseudosecond-order kinetic (1).

\section{Langmuir and Freundlich isotherms}

The plot of Langmuir and Freundlich isotherm models are shown in Figures 13 and 14, respectively, while Table 4 gives a summary of the isotherm parameters and regression coefficients at $303 \pm 1 \mathrm{~K}$.

The maximum adsorption capacity $\left(q_{\max }\right)$ of the adsorption of $\mathrm{Cd}(\mathrm{II})$ ions onto the functionalized carbon dot was obtained as $0.97 \mathrm{mg} / \mathrm{g}$. The Langmuir constant $\left(\mathrm{K}_{\mathrm{L}}\right)$ was obtained as $0.24 \mathrm{~mL} / \mathrm{mg}$ and describes the binding site affinity of $\mathrm{Cd}(\mathrm{II})$ ions onto the functionalized carbon dot. The equilibrium parameter $\left(R_{L}\right)$ was evaluated using the Langmuir constant $\left(\mathrm{K}_{\mathrm{L}}\right)$ as shown in Equation 12 and predictively shows the degree of affinity of the sorbent and the sorbate in sorption processes.

$$
R_{L}=\frac{1}{1+K_{L} C_{0}}
$$

Here, $C_{o}$ represents initial $\mathrm{Cd}(\mathrm{II})$ ions concentration and $\mathrm{K}_{\mathrm{L}}$ the Langmuir constant.
The value of $R_{L}$ determines the nature of Langmuir isotherms and generally when $R_{L}=0$, the isotherm is irreversible, if $R_{L}>1$, then it is unfavorable, if $R_{L}=1$, then it is linear but if $0<R_{L}<1$ then it is favorable (22). Evaluating $R_{\mathrm{L}}$ from the experimental data revealed that the values are in the range of 0.009 to 0.405 indicating a favorable adsorption process of $\mathrm{Cd}(\mathrm{II})$ ion on the functionalized carbon dot. The regression coefficient $\left(R^{2}\right)$ of 0.985 obtained from the plot suggested that experimental data fitted well into the Langmuir isotherm. Based on the value of the regression coefficient and dimensionless constant equilibrium parameter, the experimental data could be said to conform to the Langmuir isotherm model. The implication is that monolayer coverage of the finite number of adsorption sites on the functionalized carbon dot is prominent with uniform and equivalent adsorption sites. Interaction between the adsorbed molecules is impaired and the adsorption of $\mathrm{Cd}(\mathrm{II})$ ions onto the functionalized carbon dot is inconsequential of the occupied nearby sites $(1,22,26)$. The implication is that at the point of saturation or maximum adsorption at the adsorptive site of the functionalized carbon dot, further adsorption is quenched or hindered.

Freundlich adsorption capacity $\left(\mathrm{K}_{\mathrm{f}}\right)$ value was determined at $303 \pm 1 \mathrm{~K}$ to be $13.24 \mathrm{mg} / \mathrm{g}$. The Freundlich adsorption strength ( $n$ ) which indicates the degree of nonlinearity between the adsorption process and concentration of solution was 0.229 . Consequently, if $n=1$, adsorption process was linear, if $\mathrm{n}<1$, adsorption process was chemisorption while if $\mathrm{n}$ $>1$, adsorption process was physisorption (22). Based on the value of $n$, the adsorption process is basically physisorption. The regression coefficient $\left(R^{2}\right)$ value was 0.950 which suggested close fit of the experimental data into the Freundlich isotherms. 
The experimental data fitted well into both Langmuir and Freundlich isotherm models which is consistent with other studies on carbon dot nanomaterials (1) though a close consideration of the $R^{2}$ values indicated higher values for Langmuir (0.985) than for Freundlich (0.950). This implies that the nanomaterial is versatile and adsorption involves both monolayer and multilayer processes.

\section{Pseudo-first-order and Pseudo-second-order kinetic models}

The plot of $\log \left(\mathrm{q}_{\mathrm{e}}-\mathrm{q}_{\mathrm{t}}\right)$ against time $(\mathrm{t})$ for pseudo-firstorder kinetic model is shown in Figure 15 while the plot of $t / q_{t}$ against $t$ for pseudo-second-order kinetic model is shown in Figure 16. The equilibrium rate constants $\mathrm{K}_{1}\left(\mathrm{~min}^{-1}\right)$ and $\mathrm{K}_{2}(\mathrm{~g} / \mathrm{mg} \cdot \mathrm{min})$ and calculated adsorption capacity values are shown in Table 4 . Based on the regression coefficients and kinetic parameters, the adsorption kinetics could be said to follow the pseudo-second-order kinetics. A clear investigation indicated that the $\mathrm{K}_{1}\left(\mathrm{~min}^{-1}\right)$ is 25.609 but $\mathrm{q}_{\mathrm{e}}(\mathrm{mg} / \mathrm{g})$ was negative (-1.055), indicating the undesirability of the kinetic model even though the $\mathrm{R}^{2}$ value was high (0.996). The equilibrium rate constant of the linearized pseudo-second-order kinetic model $\left(\mathrm{K}_{2}\right)(\mathrm{g} / \mathrm{mg} \cdot \mathrm{min})$ and adsorption capacity $\left(\mathrm{q}_{\mathrm{e}}\right)$ were obtained to be 0.544 and 11.49 respectively with $\mathrm{R}^{2}$ value of 0.993 . The adsorption process shows an interplay of physisorption and chemisorption common among carbon dots nanomaterials (1) with rate controlling step likely to involve electron pair donoracceptor interactions, hydrogen bonding and dipoledipole interactions.

Table 4: Isotherms, kinetic parameters, and regression constants.

\begin{tabular}{llll}
\hline Models & Parameter 1 & Parameter 2 & $\mathrm{R}^{2}$ \\
\hline Langmuir & $\mathrm{q}_{\mathrm{m}}\left(\mathrm{mg} \mathrm{g}^{-1}\right)=0.97$ & $\mathrm{~b}\left(\mathrm{~L} \mathrm{mg}^{-1}\right)=0.24$ & 0.9850 \\
Freundlich & $\mathrm{n}=0.299$ & $\mathrm{~K}_{\mathrm{F}}\left(\mathrm{mg} \mathrm{g}^{1-1 / \mathrm{n}} \mathrm{L}^{1 / \mathrm{n}} \mathrm{g}^{-1}\right)=-$ & 0.9500 \\
& & 13.24 & \\
Langmuir & $\mathrm{qe}\left(\mathrm{mg} \mathrm{g}^{-1}\right)=25.609$ & $\mathrm{~K}_{1}\left(\mathrm{~min}^{-1}\right)=25.609$ & 0.9960 \\
Freundlich & $\mathrm{qe}\left(\mathrm{mg} \mathrm{g}^{-1}\right)=11.49$ & $\mathrm{~K}_{2}\left(\mathrm{~g} / \mathrm{mg} \mathrm{min}^{2}=\right.$ & 0.9930 \\
& & 0.544 & \\
\hline
\end{tabular}

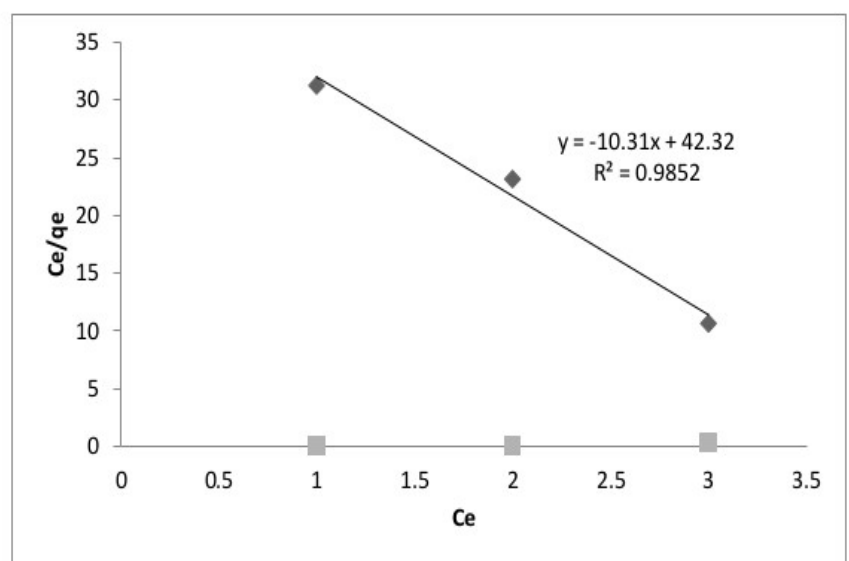

Figure 13: Langmuir adsorption isotherm plot of (Ce/qe) versus $\mathrm{Ce}$ for the adsorption of $\mathrm{Cd}(\mathrm{II})$ ions onto Functionalized carbon dot at pH 5 and $303 \pm 1 \mathrm{~K}$.

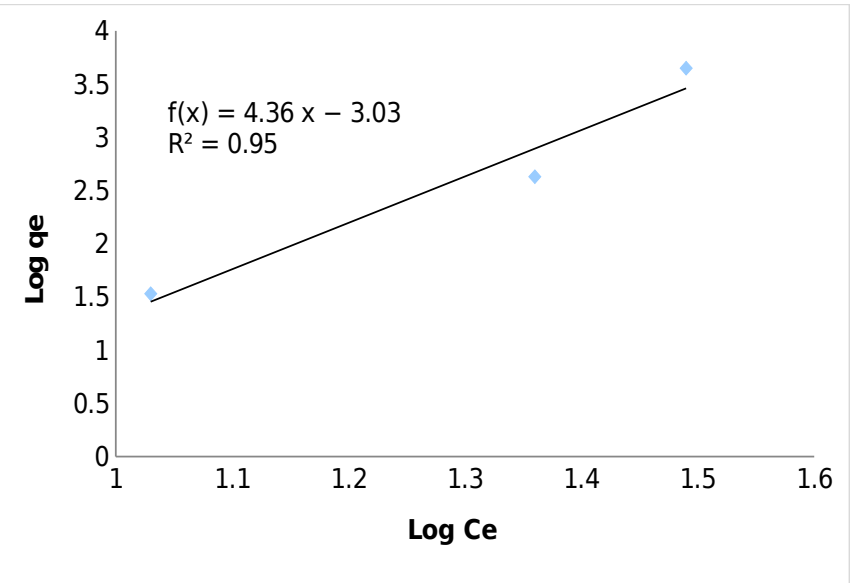

Figure 14: Freundlich adsorption isotherm plot of log qe versus log Ce for the adsorption of $\mathrm{Cd}(\mathrm{II})$ ions onto Functionalized carbon dot at $\mathrm{pH} 5$ and $303 \pm 1 \mathrm{~K}$. 


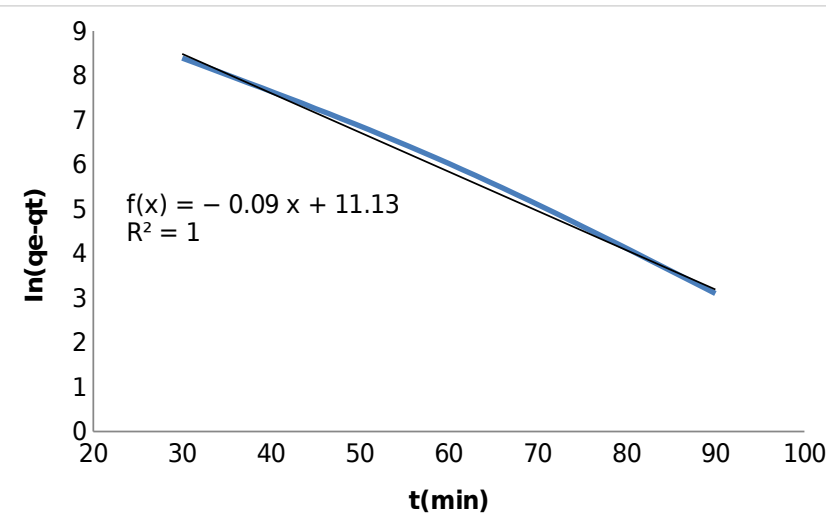

Figure 15: Pseudo-first-order kinetic plot of $\ln \left(q_{\mathrm{e}}-\mathrm{q}_{\mathrm{t}}\right)$ versus $\mathrm{t}$ for the adsorption of $\mathrm{Cd}(\mathrm{II})$ ions onto the functionalized carbon dot at pH 5 and $303 \pm 1 \mathrm{~K}$.

Possible mechanism of $\mathrm{Cd}(\mathrm{II})$ chelation and removal using the functionalized carbon dot Previous work (27) suggests that $\mathrm{Cd}(\mathrm{II})$ forms extractable complex of the type $\mathrm{Cd}\left(\mathrm{H}_{2} \mathrm{SAL}\right)$ in the mole ratio of ligand to metal of $1: 1$. The quantitative removal of cadmium(II) from aqueous solution of $\mathrm{pH}$ 10-11 could be as a result of chelation with the dissociated $\mathrm{HSAL}^{-}$and $\mathrm{SAL}^{2-}$ on the surface of the functionalized carbon dot nanoparticle. At higher $\mathrm{pH}$ and in the dissociated form, $\mathrm{H}_{2} \mathrm{SAL}$ on the biointerface of the functionalized carbon dot is chelated with $\mathrm{Cd}$ (II) ions in solution through the lone electron pair resident on the oxygen and nitrogen atoms of the $\mathrm{H}_{2} \mathrm{SAL}$ moeity and imine group, respectively. At lower $\mathrm{pH}$, and in the protonated form, $\left[\mathrm{H}_{4} \mathrm{SAL}\right]^{2+}$ or $\left[\mathrm{H}_{3} \mathrm{SAL}\right]^{+}$, the $\mathrm{H}_{2} \mathrm{SAL}$ on the biointerface of the functionalized carbon dot may exist as protonated cationic complex with $\mathrm{Cd}$ (II) ions.

The competition between the $\mathrm{Cd}(\mathrm{II})$ ions in solution and the hydronium ions formed at $\mathrm{pH} 2-4$ resulted in instability of the cationic complex formed and consequent regress in the amount of $\mathrm{Cd}(\mathrm{II})$ adsorbed (28). At pH 5, increase in the competition between the $\mathrm{Cd}(\mathrm{II})$ ions and the hydronium ions in solution disappears and stable cationic complex is formed leading to increase in the amount of $\mathrm{Cd}(\mathrm{II})$ removed. The $\mathrm{pK}_{a}$ of $\mathrm{Cd}(\mathrm{II})$ is 10.1 with $\mathrm{M}^{2+}$ and $\mathrm{M}(\mathrm{OH})^{+}$as the dominant species at $\mathrm{pH} 5$ and as shown in equations 13-15. At higher $\mathrm{pH}$ of 10-11, possibility of increase in the quantity of $\mathrm{Cd}(\mathrm{II})$ adsorbed due to formation of stable metal hydroxo species exist. Cadmium(II) ions

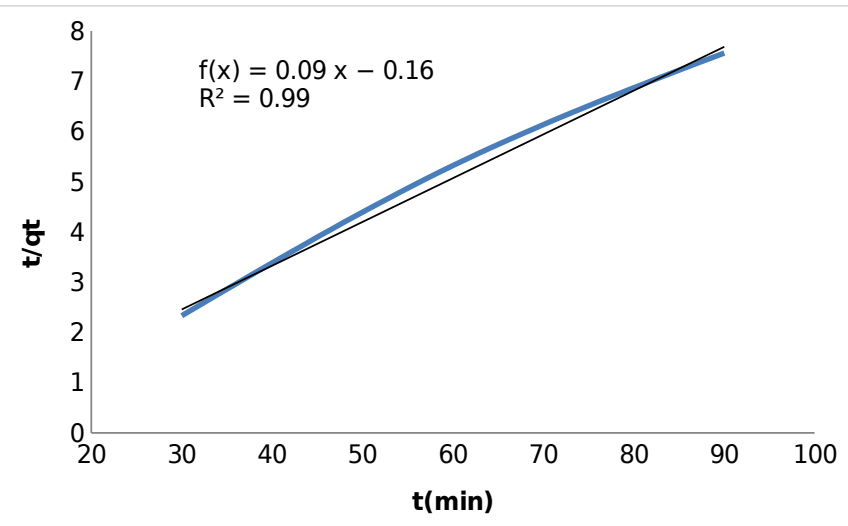

Figure 16: Pseudo-second- order plot of $t / q_{t}$ versus $t$ for the adsorption of $\mathrm{Cd}(\mathrm{II})$ ions onto functionalized carbon dot at pH 5 and $303 \pm 1 \mathrm{~K}$.

tend to hydrolyze at $\mathrm{pH} 10-11$ and formation of stable hydroxo complexes of cadmium with the ligand exist leading to increased extraction of cadmium from solution. Precipitation of $\mathrm{Cd}(\mathrm{OH})_{2}$ lowers adsorption, but in this case chelation and formation of stable hydroxo complexes of $\mathrm{Cd}$ (II) ions could have likely won over the former process.

$$
\begin{gathered}
\mathrm{M}^{2+}+\mathrm{n} \mathrm{H}_{2} \mathrm{O} \rightarrow \mathrm{M}\left(\mathrm{H}_{2} \mathrm{O}\right)_{n}{ }^{2+} \\
\mathrm{M}\left(\mathrm{H}_{2} \mathrm{O}\right)_{n}{ }^{2+} \leftrightarrow\left[\mathrm{M}\left(\mathrm{H}_{2} \mathrm{O}\right)_{n-1}(\mathrm{OH})\right]^{+}+\mathrm{H}^{+} \\
\mathrm{M}^{2+}+\mathrm{n} \mathrm{H}_{2} \mathrm{O} \leftrightarrow\left[\mathrm{M}\left(\mathrm{H}_{2} \mathrm{O}\right)_{n-1}(\mathrm{OH})\right]^{+}+\mathrm{H}^{+}
\end{gathered}
$$

\section{Comparison with other adsorbents}

Table 5 shows the adsorption capacity of some biomaterials in comparison with carbon dot. The initial concentration of the metal used is lower for carbon dot sorption as surveyed from various studies. However, carbon dot exists in nano form as against some of the adsorbent. The adsorption capacity of the SALEN functionalized carbon dot seems to be lowest for the carbon dot in comparison to the listed biomaterials. Possible influence of extraneous variables may be a factor. However, the concentrations of initial cadmium for the studied biosorbents was not available for effctive comparison. Other studies for the sorption of lead using carbon dot used low lead concentration without evaluation of sorption capacity (1). 
Table 5: Comparison of the adsorption capacity of impregnated biomaterials for the sorption of Cd(II) ions from

\begin{tabular}{|c|c|c|c|c|}
\hline \multicolumn{5}{|c|}{ Adsorption } \\
\hline & source & Soparm & capacity & 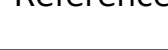 \\
\hline 1 & Corn straw & $\mathrm{MnFe}_{2} \mathrm{O}_{4}$ & $\begin{array}{l}127.83 \\
\mathrm{ma} / \mathrm{a}\end{array}$ & (29) \\
\hline 2 & Spent coffee & $\begin{array}{l}\text { sodium dodecyl } \\
\text { sulfate }\end{array}$ & $\begin{array}{l}10.67 \mathrm{mg} / \\
\mathrm{g}\end{array}$ & (30) \\
\hline 3 & Wheat straw & $\mathrm{CS}_{2} / \mathrm{NaOH}$ & N/A & (31) \\
\hline 4 & Bamboo & $\mathrm{NH}_{3} / \mathrm{ZnCl}_{2}$ & $\begin{array}{l}44.54 \mathrm{mg} / \\
\mathrm{g}\end{array}$ & (32) \\
\hline 5 & Plantain peel & SALEN & $\begin{array}{l}8220 \\
\mathrm{mg} / \mathrm{kg}\end{array}$ & (33) \\
\hline 6 & Banana waste & SALEN & $0.97 \mathrm{mg} / \mathrm{g}$ & This work \\
\hline
\end{tabular}

\section{Regeneration/Reusability of the used nanocomposites \\ The reusability of the SALEN functionalized adsorbent} was evaluated after regeneration of the used composite using different concentrations of $\mathrm{HCl}$. Variation of concentrations of $\mathrm{HCl}$ from 1-0.0001 $\mathrm{M}$, equilibration time between $5-30 \mathrm{~min}$ and volume of solution between $5-10 \mathrm{~cm}^{3}$ indicated that equilibration of $0.1 \mathrm{~g}$ of used sorbent with $5 \mathrm{~cm}^{3}$ solution at $\mathrm{HCl}$ concentration of $1 \mathrm{M}$ and time of contact of $10 \mathrm{~min}$ gave maximum desorption of used sorbent. Single extraction was applied and result shows that at high acid concentration, demetallation, and ligand degradation of the SALEN-carbon dot composite occurred freeing the metal from the sorbent. To ensure the reusability of composite, desorption adsorption study was conducted and result obtained after four times of batch processes decreased only by $9-15 \%$.

\section{CONCLUSION}

A facile method was used for the preparation of highly fluorescent functionalized carbon dot nanoparticle for application in optical sensors and in extraction of $\mathrm{Cd}$ (II) ion from aqueous solution. The parameters for estimating the optical sensitivity of nanomaterials as applied to the newly synthesized nanoparticle indicated that the carbon dot and its SALEN functionalized counterpart are highly optically sensitive and of strong photoluminescence ability. The metal chelation and removal property studied indicated that the nanosized material is highly efficient, versatile and effective in the removal of Cd(II) ions (99.3\%) and could be extended for the removal of other heavy metals and environmental toxicants from matrices. The results obtained indicated the preparation of an environmentally friendly carbon based nanomaterial that is safe, highly fluorescent, versatile and reusable nanocomposite that could serve as biomarkers for tracing and removal of environmental cadmium contamination.
The authors declare no conflict of interest in the manuscript submission

\section{ACKNOWLEDGMENT}

The authors are grateful to Ebonyi State University, Abakaliki for TETFund grant (Ref No:EBSU/TETFund/IBR/2015/10) financial assistance.

\section{REFERENCES}

1. Musa YP, Zurina Z A, Suraya A R, Faizah $M$, Noor A S M, Mohammed A I. Eco-Friendly Sustainable Fluorescent Carbon Dots for the Adsorption of Heavy Metal Ions in Aqueous Environment. Nanomaterials. 2019; 10:315. https://doi.org/10.3390/nano10020315

2. Waalkes M P (2000) Cadmium carcinogenesis in review. J. Inorg. Biochem. 2000; 79(1-4): 241-4. https://doi.org/10.1016/S0162-0134(00)00009-X

3. Scimeca M, Feola M, Romano L, Rao C, Gasbarra E, Bonanno E. Heavy metals accumulation affects bone microarchitecture in osteoporoticpatients. Environ Toxicol. 2017;32:

https://doi.org/10.1002/tox.22327

1333-42.

4. Ghorbani M, Eisazadeh $H$. Removal of COD, color,anions and heavy metals from cotton textile waste water by using polyaniline and polypyrrole nanocomposites coated on rice husk ash.Composites B: $\quad$ Eng.2015; $45(1)$ : 1 https://DOI: 10.1016/j.compositesb.2012.09.035

5. Banerjee S, Chattopadyaya MC. Adsorption characteristics for the removal of a toxic dye, tartrazine from aqueous solutions by a low cost agricultural by-product. Arabian Journal of 
Chemistry.2017; https://doi.org/10.1016/ j.arabjc 2013.06.005

10:S1629-S1638.

6. Moyakhe D, Waanders F.B, Le Roux M, Campbell M.Q. The Journal of the Southern African Institute of Mining and Metallurgy. 2019 ; 119 : 607-12.

7. Khan A S, Dhevagi, P, Chitdeshwari P, Avudainayagam $S$ (2018) Bio-sorption of cadmium from Aqeous solutions by banana peel powder. Madras Agric Journal.2018; 105(1- 3): 24-9. https://DOI: 10.29321/MAJ.2018.000096

8. Abdolali A, Ngo HH, Guo W, Lu S, Chen SS, Nguyen NC, Zhang $X$, Wang J, Wu Y.A breakthrough biosorbents in removing heavy metals: equilibrium, kinetic, thermodynamic and mechanism analyses in a lab-scale study. Sci Total Environ.2016;542:603-11. https://doi.org/10.1016/j.scitotenv.2015.10.095

9. Tao S, Lu S, Geng Y, Zhu S, Redfern SAT, Song $Y$, Feng $T$, Xu W, Yang B. Design of metal-free polymer carbon dots: a new class of room-temperature phosphorescent materials Angew. Chem. Int. Ed. 2018; 57: 2393-8. https://doi.org/10. 1002/anie.201712662

10. Kong W.Quantitative and real-time effects of carbon quantum dots on single living HeLa cell membrane permeability. Nanoscale.2014; 6: 5116-20. https ://doi.org/10.1039/ C3N R06590A

11. Chen $Y$, Zheng $M$, Xiao $Y$, Dong $H$, Zhang $H$, Zhuang J, Hu H, Lei B, Liu Y. (2016). A self-quenchingresistant carbon-dot powder with tuneable solid-state fluorescence and construction of dual-fluorescence morphologies for white light-emission. Adv. Mater.2016; 28: 312-8. http://doi.org/ 10.1002/adma.201503380

12. Hu S. Tunable photoluminescence across the entire visible spectrum from carbon dots excited by white light. Angew. Chem. Int. Ed.2015; 54: 2970-4. https://DOI: 10.1002/anie.201411004

13. Ge J. Red-emissive carbon dots for fluorescent, photoacoustic, and thermal theranostics in living mice. Adv. Mater.2015; 27: 4169-77. . https:// DOI:10.1002/adma.201500323

14. Young AT. Neuro-nano interfaces: Utilizing nanocoatings and nanoparticles to enable next-generation electrophysiological recording, neural stimulation, and biochemi-cal modulation. Adv. Funct. Mater. 2018; 28: 1700239.https://doi.org/ 10.1002/ adfm. 201700239

15. Hola K. Graphitic nitrogen triggers red fluorescence in carbon dots. ACS Nano. 2017; 11: 12402-10. https://DOI: 10.1021/acsnano.7b06399

16. Nworie FS, Nwabue FI. Synthesis, Optimization, Characterization and Antimicrobial Studies of Cu (II) and Co (III) Complexes of $\mathrm{Bis}(2,2 /$-methylylidene phenol) diaminoethane. Chemistry Journal of Moldova, General, Industrial and Ecological Chemistry.2017; 12(2): 41-9. .https:// DOI: 10.19261/ cjm.2017.392

17. Kezerle A, Velic N, Hasenay K D(2018) Lignocellulosic materials as adsorbents: Adsorption of MEB and Congo red on brewers spent grain. Croat. Chem. Acta.2018; 91:53-64. https://doi.org/10.1016/j.jhazmat.2019.120897

18. Mokkapati RP, Ratnakaram VN, Mokkapati JS. Utilization of agro-waste for removal of toxic hexavalent chromium: surface interaction and mass transfer studies. Int,J. Environ. Sci. Technol. 2017; 10:017-037. https://DOI:10.1007/s13762-017-1443-

19. Li H. Water-soluble fluorescent carbon quantum dots and photocatalyst design. Angew. Chem. Int. Ed. 2010; 49: 4430-4. https://doi.org/10.1002/anie.200906154

20. Chen BC, Li CD, Zhang J, Kan JF, Jiang TT, Zhou J, Ma HM. Sensing and imaging of

mitochondrial viscosity in living cells using a red fluorescent probe with a long lifetime. Chem Commun.2019; 55:7410-3.

https://doi.org/10.1039/C9CC03977E

21. Arcudi F. Rationally designed carbon dots nanodots towards pure white light emission. Angew. Chem. Int. Ed.2016; 56: 4170-3. https://doi.org/10.1002/anie.201612160

22. Nworie FS, Nwabue F, Ikelle I, Ogah A, Elom N, llochi N, Itumoh E, Oroke C. Activated plantain peel biochar as adsorbent for sorption of Zinc (II) ions: Equilibrium and kinetic studies. Journal of the Turkish Chemical Society, Section A.2018; 5(3), 1257-70. http://dx.doi.org/10.18596/jotcsa.438332.

23. Zhao G, Li J, Ren X, Chen C, Chen X. Few-layered graphene oxide nanosheets as superior sorbents for heavy metal ion pollution management. Environ. 
Sci.Technol.2011; 45(24): 10.1021/es203439v.

10454-62. https:// doi:

24. Ghaedi M, Montazerozohori M, Soylak M. Solid phase extraction method for selective determination of $\mathrm{Pb}(\mathrm{II})$ in water samples using 4-(4methoxybenzylidenimine) thiophenole. Journal of Hazardous Materials.2017; 142: 368-73. https://doi.org/10.1016/j.jhazmat.2006.08.033

25. Haruna A, Abdulkadir I, Idris S O. Synthesis, Characterization and Photocatalytic Properties of Bi0.85-XMXBa0.15FeO3 ( $\mathrm{M}=\mathrm{Na}$ and $\mathrm{K}, \mathrm{X}=0,0.1$ ) Perovskite-like Nanoparticles Using the Sol-gel Method. Journal of King Saud University Science .2020; 32(1): 896-903.

26. Haruna A, Abdulkadir I, Idris S O. Photocatalytic activity and doping effects of $\mathrm{BiFeO} 3$ nanoparticles in model organic dyes. Heliyon. 2020; e03237.

27. Nworie FS. Spectral, Thermal and In Vitro Antibacterial Studies on Cadmium(II)-bis(2,2/methylidenephenol)diaminoethane. Journal of the Turkish Chemical Society Section A: Chemistry.2018;5 (3): 1029-36. https://doi.org/10.18596/jotcsa.423508

28. Nworie FS, Nwabue FI. Synthesis, Optimization, Characterization and Antimicrobial Studies of $\mathrm{Cu}$ (II) and Co (III) Complexes of $\operatorname{Bis}(2,2 /$ methylylidenephenol) diaminoethane. Chemistry Journal of Moldova, General, Industrial and Ecological Chemistry.2017; 12(2): 41-9 .https:// DOI: 10.19261/ cjm.2017.392
29. Zhang L, Guo J, Huang X, Wang W, Sun P, Lib Y, Han J. Functionalized Biochar-Supported Magnetic MnFe2O4 Nanocomposite for the Removal of $\mathrm{Pb}(\mathrm{II})$ and $\mathrm{Cd}(\mathrm{II})$. RSC Adv. 2019; 9: 365 DOI: 10.1039/ c8ra09061k

30. Moyakhe D, Waanders FB, Le Roux M, Campbell Q P. Hydrothermal Preparation of Biochar from Spent Coffee Grounds, and its Application for the Removal of Cadmium from Coal Tailings Leachate. The Journal of the Southern African Institute of Mining and Metallurgy.2019; 119: 607-12 DOI: 10.17159/2411-9717/449/2019.

31. Chen D, Wang X, Wang X, Feng K, Su J, Dong J.The mechanism of cadmium sorption by sulphurmodified wheat straw biochar and its application cadmium contaminated soil. Science of The Total Environment. 2020; $\quad 714: 136550$ https://doi.org/10.1016/j.scitotenv.2020.136550

32. Tang W, Cai N, Xie H, Liu Y, Wang Z, Liao Y, Wei $\mathrm{T}$, Zhang C, Fu Z,Yin D. Efficient Adsorption Removal of $\mathrm{Cd} 2+$ from Aqueous Solutions by $\mathrm{HNO}_{3}$ Modified Bamboo-Derived Biochar. Materials Science and Engineering. 2020; 729: 012081

33. Nworie F S, Nwabue F I, Oti W, Omaka N O, Igwe $\mathrm{H}$. Hydrothermal Synthesis of Multifunctional Biocharsupported SALEN Nanocomposite for Adsorption of $\mathrm{Cd}$ (II) Ions: Function, Mechanism, Equilibrium and Kinetic Studies. Anal. Bioanal. Chem. Res.2020; 8(1): 91-112. 
Nworie FS, Ebunoha JI. JOTCSA. 2021; 8(1): 137-154.

RESEARCH ARTICLE 